\title{
Proceeding
}

\section{The impact of theory to study the Al-Biomechanics skill in the performance of jumping on a groundbreaking platform to jump in artistic gymnastics for students}

\author{
FERDOUS MAJEED AMEEN ${ }^{1}$, SURA JAMIL HANNA², HEIDER SAUD HASSAN ${ }^{1}$ \\ ${ }^{1}$ College of Physical Education, University of Diyala \\ ${ }^{2}$ Collage of Physical Education, University of Duhok
}

\begin{abstract}
Majeed, F., Jamil, S., \& Saud, H. (2015). The impact of theory to study the Al Biomechanics skill in the performance of jumping on a groundbreaking platform to jump in artistic gymnastics for students. J. Hum. Sport Exerc., 10(Proc2), pp.S648-S656. To understand the information related to movements in terms of biomechanical sports is one of the essential ingredient in the success and development of these movements, so the interest in studying this information can give positive returns in the process of education, training, methods of teaching skills and athletic movements. This depends on the capabilities, experience and attitudes of dealing with this information, mechanical, which they depend, in determining the learning objectives as an initial stage of a substance gymnastics. From this port, the researchers wanted to see the problem difficulty level of the students in the development of some key events of a substance artistic gymnastics after their studies the Biomechanics material and access to information on the performance skills of gymnastics movements. The Biomechanics through information obtained by the students of the second phase of the Faculty of Physical Education University of Diyala and their number (40) student, researcher aims to identify the effectiveness of information theory on the application of technical performance and the level of attainment in the skill of jumping on a groundbreaking platform jumping. And to identify the differences between before and after in the level of performance and achievement in the skill of jumping opened. And imposed the existence of statistically significant differences in the stages of the level of attainment technical performance of the skill of jumping on a groundbreaking platform jumping. By the results the researcher concluded: And to identify the differences between before and after in the level of performance and achievement in the skill of jumping opened. And imposed the existence of statistically significant differences in the stages of the level of attainment technical performance of the skill of jumping on a groundbreaking platform jumping. By the results the researcher concluded: That the information theory of Biomechanics obtained by the student influence in improving the performance of the skill level to jump on a groundbreaking platform to jump in artistic gymnastics for girls. Key words: PLATFORM, JUMP, ARTISTIC GYMNASTICS.
\end{abstract}

Corresponding author. College of Physical Education, University of Diyala, Jadriyah, Baghdad, Irak Asia Pacific Conference on Performance Analysis of Sport, 21-24 April 2014. Langkawi, Malaysia. JOURNAL OF HUMAN SPORT \& EXERCISE ISSN 1988-5202

(c) Faculty of Education. University of Alicante doi:10.14198/jhse.2015.10.Proc2.02 


\section{DEFINITION OF RESEARCH}

Introduction of research and the importance of:

Considered material Biomechanics science material outstanding scientific taught in the field of Physical Education also has a special place in the field of sports, especially in education and training and other has credit for continuing progress in the sports in which are analyzed movements and mathematical skills, and through which also correct technical errors and innovation What is new movements better and better in the field of sports and all its activities. Therefore, we find that with this great science entered the game with gymnastics characterized by difficulty skill performance by the players, as well as students of the Faculty of Physical Education.

So we find that the science of Biomechanics contribute to the analysis, to clarify ,explain, and improve the technique sports, which is one of the most important science through which to evaluate the skills, which is the scientific basis must be followed to get to know many of the details that explain precisely how to correct tracks motor that accompanies performance which can not be judged by mere observation of self, but require the use of assistive devices to get to a place errors to avoid them and find out the strengths and weaknesses through kinetic analysis, and this does not happen only through retail traffic to their positions overlapping, and then determine the nature of each part of the movement. "(2)

The sport of gymnastics sports that their performance depends to the development of the player or the student requirements for all private side mechanical and kinetic analysis.

So is the importance of research in the diagnosis of skill which is given to students of the second phase according to the proper characteristics Al-Biomechanics which is linked to the skill performed by competent school gymnastics and then the game continued to avoid errors in the body in terms of the angles of rotation or mechanical or kinetic entire track students with the second phase. So you should start the process of explanation and correction of errors initially However backs video imaging psychomotor skills so as to ensure that the student start-up to be closer than ideal performance.

\section{Search a problem:}

The Biomechanics science of science very difficult compared with materials Phase II study for the students of the Faculty of Physical Education because they contain material physics and mathematics as well as the analysis of the movements, as well as note the difficulty of the vocabulary of material gymnastics in order to contain several skills make it difficult for student performance, and also notes that many of the movements are accompanied by technical errors the researcher found and taught through articles (Al-Biomechanics and gymnastics ) that the information that is given to students of the second stage between science AlBiomechanics gymnastics and play together gives the best effect and results in the development of the skills of the student 's performance and improve the scientific level in Biomechanics. So the problem is limited to the impact of research in information Al-bayumkanikih in developing the level of performance and achievement in artistic gymnastics for the students of the second phase.

The research aims:

Identify the effectiveness of information the theoretical to study the performance of the Biomechanics skill opened jumping on a machine platform jumping.

\footnotetext{
2 - Mohammed Jaber, Mohamed Yehia Ghaida: modified method to catch fingers tug in the sport of archery, research published in the Faculty of Physical Education for Boys, Alexandria University. 2004. P. 64
} 
Search impose:

There are significant differences between the tests before and after the performance skills and theoretical skill to jumping on a machine opened platform jumping after getting information Biomechanics.

The areas of research:

The human sphere:

Students in the Faculty of Physical Education / University of Diyala, of their number (40) female students.

Temporis sphere:

The domain: 1/2/2012 until 15/3/2012.

The spatial domain:

The laboratory Study for the Biomechanics and artistic gymnastics hall at the College of Physical Education I University of Diyala.

\section{THE THEORETICAL STUDIES}

Device platform jumping:

He machine consists of three parts in the field of jogging a specific a distance $25 \mathrm{~m}$ by of international law for gymnastics and panel the glove which length $(120 \mathrm{~cm})$ and display $(60 \mathrm{~cm})$ and height $(20 \mathrm{~cm})$ platform and jumping which in length $(120 \mathrm{~cm})$ and display $(95 \mathrm{~cm})$ and height $(135 \mathrm{~cm})$ for men $(125 \mathrm{~cm})$ for women must result the player a jump and one in the championships all of except the Championship a final devices where it needs to displays the quantum leaps of the two different sets of groupware the kinetic platform jumping. And on the player begin all the a jump than standing fixed. The two men stretched out facing the platform and jumping as in the form of (1).

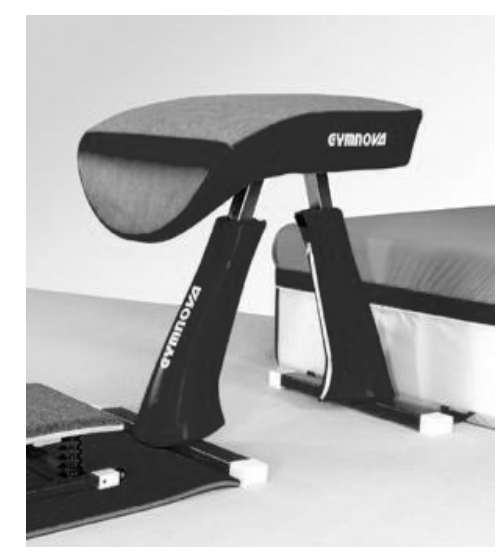

Figure 1. Platform

Skill opened jumping on a machine horse jumping

The player running around a distance of no more than (20) and starts running on Combs feet steps regularly an increasingly in speed until it reaches the maximum speed in the last steps that precede the advancement. Upon the arrival player into panel jumping is beat her and the advancement of the body back a little bit and be a force explosive seemed to aviation first then swing the two legs succeeding aloft namely and Outstretched or to arrive above the horizontal level to the surface of the podium and the two arms are 
moving to the front top and the puts the body a straight line italic and look at the surface of the focal and the are placed hands are before the end of the device with little stretched out or and the Open the shoulder displays then pays player strongly when it device reach the shoulder girdle vertical plane over the hands, opens the two men and lift two arms aloft slashes to access the second a flight stage. The player after him annexation of two men and extend trunk and landed on Combs feet a half with a knees bend and the arm put aside and then extend the knees., as shown in Figure 2.
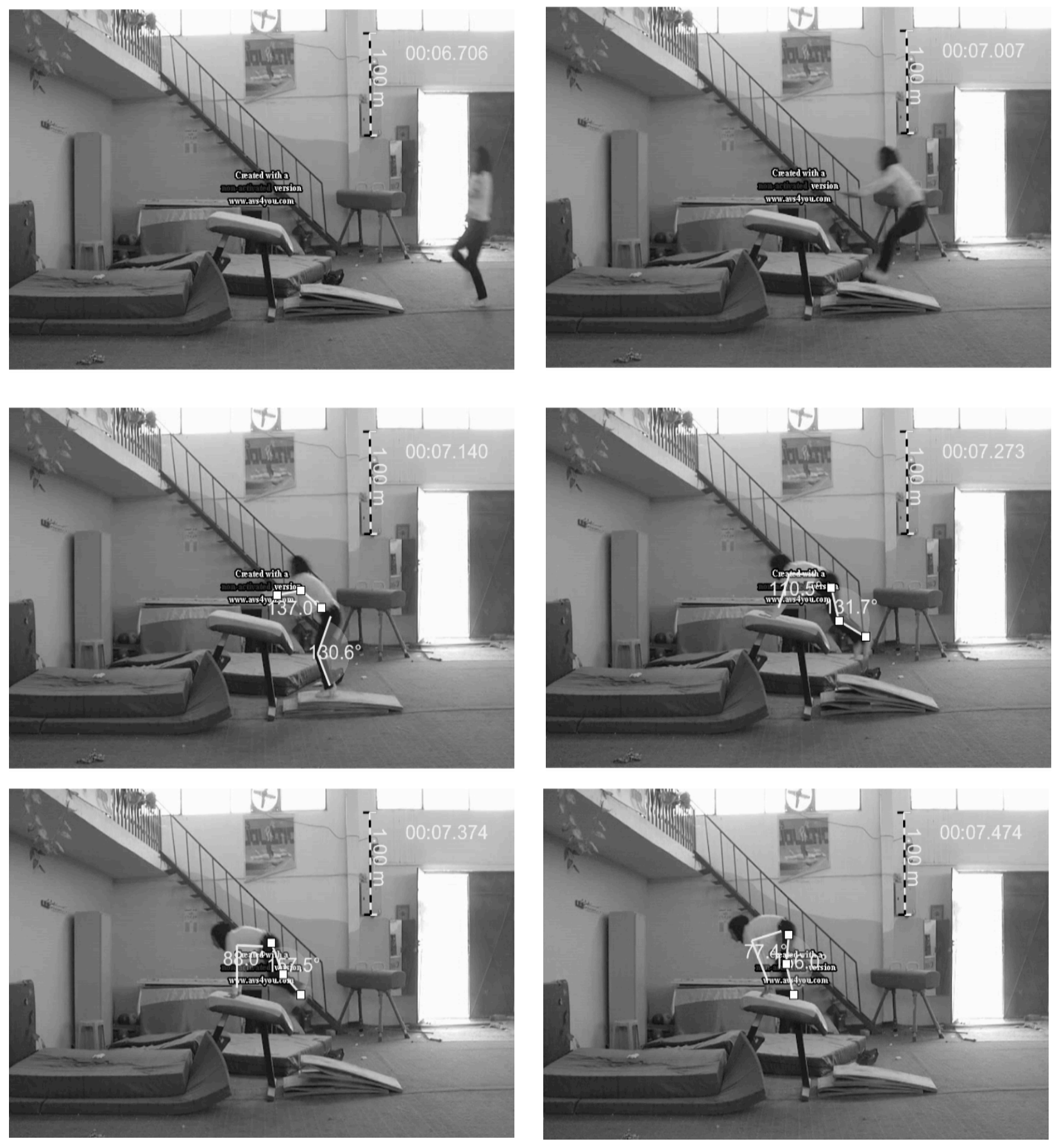

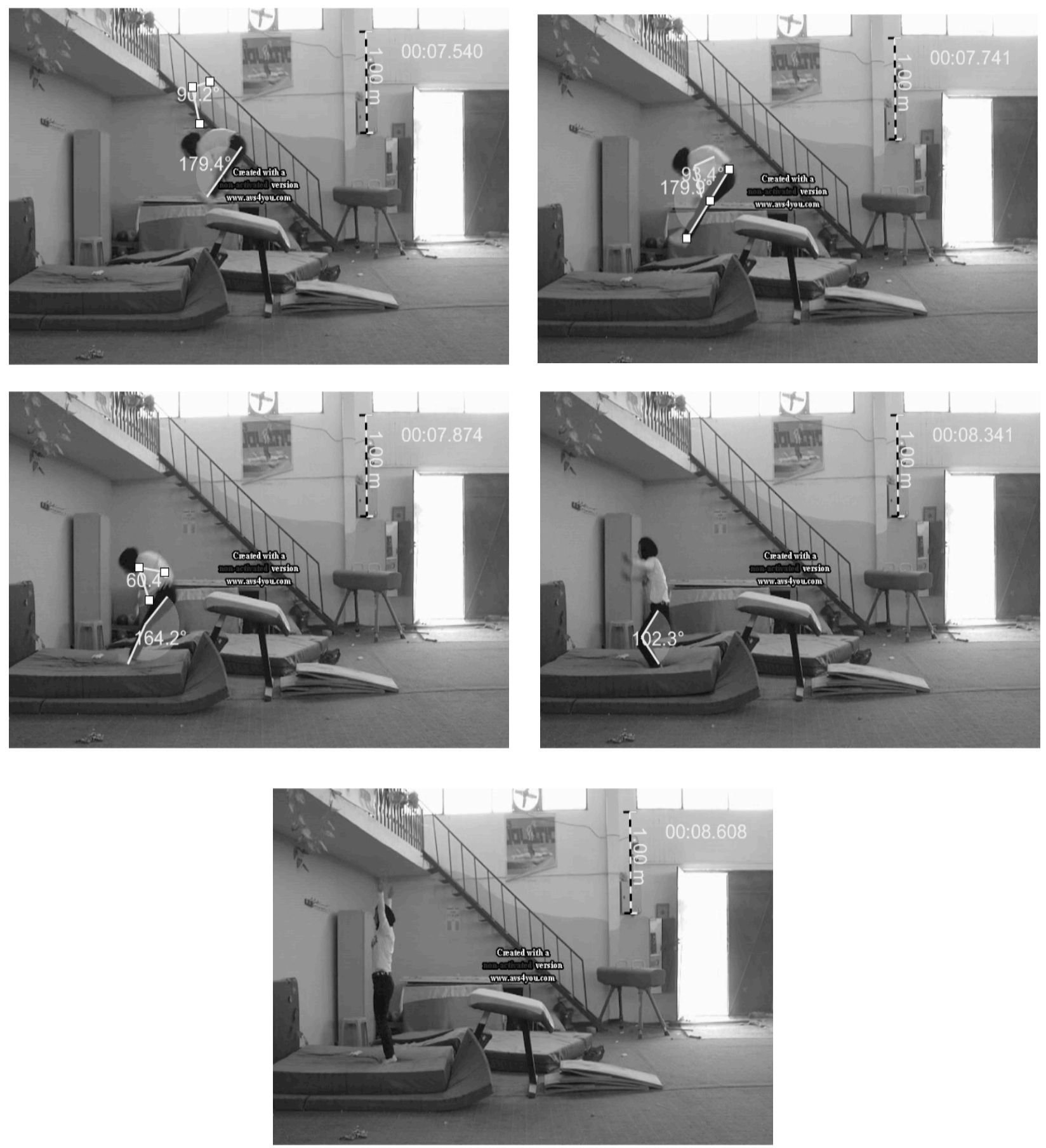

Figure 2. The figure shows skill jumping on a machine opened a platform jumping 


\section{RESEARCH APPROACH AND PROCEDURES FOR OF FIELD}

Research approach:

The researchers used a experimental method to fit the nature of problem and the research objectives.

Research society and the sample

Research society been selected in the manner of the deliberate second stage female students of the College of of Physical Education / Diyala University for the academic year 2011-2012 and of their number (40) female students research society they representing 100\%. , Has been divided into two groups equally

Table (1). Shows the Equalization of experimental and control groups in the skillful performance the skill jumping device opened a platform jumping and collectable theoretical

\begin{tabular}{llllll}
\hline Tests & Groups & $\begin{array}{l}\text { The arithmetic } \\
\text { mean }\end{array}$ & $\begin{array}{l}\text { Standard } \\
\text { deviation }\end{array}$ & $\begin{array}{l}\text { The calculated } \\
\text { value of T. }\end{array}$ & $\begin{array}{l}\text { Significance of } \\
\text { differences }\end{array}$ \\
\hline Practical & Experimental & 3.35 & 0.98 & 0.16 & \\
\cline { 2 - 4 } & Standard & 3.30 & 0.97 & & Not significant \\
\hline \multirow{2}{*}{ Achievement } & Experimental & 3.90 & 1.11 & & Not significant \\
\cline { 2 - 4 } & Standard & 3.60 & 0.88 & & \\
\hline
\end{tabular}

* Value $(T)$ Tabulated at 38 degrees of freedom and the potential error $0.01=2.750$

Appliances, tools and means of gathering information

${ }^{*}$ Arab sources

* registrationformdata.

*typevideocamera(Sony)withatripod.

*videotypeNational.

*VCRtypeNational.

*devicetypedellLaptop

*softwareandapplicationsusedinthecomputer.

*deviceplatformjumping.

*aglovenumber (2).

*belts for your platform jumping.

The experimental reconnaissance:

The experiment was conducted reconnaissance in the Hall of artistic gymnastics for Physical Education College / University of Diyala. On Wednesday, 01/02/2012 at 9 am on two of the students the second phase., As longer experience path finding "practical training for the researcher to get back on negatives and positives which is offset by while working to avoid them "(3).. Which included the implementation of the method and the method of performance calendar as well as the use of film to conduct a preliminary analysis the skill in question.

Proceedings the experience the main:

Been working curriculum from Sunday day on 5/5/2012 and duration of action of the theory and practical units a week for four weeks, and through the the work was explain the skill jumping opened on a platform

3 - Qasim Mandalawi (and others); tests and measurement in physical education: (Mosul Press, Higher Education, 1990), p 107 
jumping during studied the Biomechanics on the plate then later was displayed skill Data show from the moment sprint to the approximate performance of skill and then landing. Then was converted lesson of the the theoretical to the practical was explaining the skill by the School of matter and all the steps and then performance of skill fully later was given the steps educational for the student prior to performance of skill of the sprint the approximate and then method hit the glove and how to put your hands to the right place and then teach method performance of skill-click the device and crossed the landing and then after this stage, the student performs skill fully. During the education of material the steps theoretical Biomechanics interfere in explaining skill in addition to the introduction of imaging researcher for the analysis of mechanical skill and the method their performance at work. Where the researcher to conduct filming angles motor performance of the student during the performance of the skill to show where errors put the body through which the student is to clarify the status of mechanical and correct angles to deliver the student to the stage of the proportion of mis have few or non-existent.

Accession of the skilled performance

Was rated skill performance (10) scores in the two measurements pre and post through the display skill performance after conceptual four umpires, has been deleted higher and lower grade and took the average Class remaining, and carried out this operation on the experimental and control groups in the two measurements pre and post.

Evaluation of the theoretical test

Researchers test theoretically pay Bayumkanikih skilled in jumping opened (10) scores in the the two measurements pre and post it through the presentation of papers on the test scores of three teachers in the jurisdiction of the material biomechanics gymnastics if the stock was sent by the tribal sorted into two groupsj

The final collection:

Were collected test scores and skill performance the test the theoretical attainment naming under the final.

The Statistical means

The researchers used statistical means the appropriate for the manipulate search results using the Statistics bag (spss).

\section{PRESENTATION AND ANALYSIS OF AND DISCUSS FINDINGS:}

Table (2). Shown the differences in skill performance of the experimental group and the control group in pre and post tests for the skill jumping on a machine opened a platform jumping

\begin{tabular}{|c|c|c|c|c|c|c|}
\hline Groups & Tests & $\begin{array}{l}\text { Mean } \\
\text { Arithmetic } \\
\text { Differences }\end{array}$ & $\begin{array}{l}\text { Deviation } \\
\text { Standard } \\
\text { Differences }\end{array}$ & $\begin{array}{l}\text { Value T } \\
\text { Calculated }\end{array}$ & $\begin{array}{l}\text { Level } \\
\text { Significance }\end{array}$ & $\begin{array}{l}\text { Meaning } \\
\text { Significance }\end{array}$ \\
\hline \multirow{2}{*}{ Experimental } & Pretest & \multirow{2}{*}{4.700} & \multirow{2}{*}{1.031} & \multirow{2}{*}{20.38} & \multirow{2}{*}{0.00} & \multirow{2}{*}{ Moral } \\
\hline & Posttest & & & & & \\
\hline \multirow{2}{*}{ Regulation } & Pretest & \multirow{2}{*}{2.35} & \multirow{2}{*}{0.81} & \multirow{2}{*}{12.93} & \multirow{2}{*}{0.00} & \multirow{2}{*}{ Moral } \\
\hline & Posttest & & & & & \\
\hline
\end{tabular}

* Value $(\mathrm{T})$ cross tabulated when you 19 degree of freedom and the prospect of error $0.01=2.860$ 
Table (3). Shown the differences in theoretical test experimental group and the control group in the pretest and posttest with Article the theoretica.

\begin{tabular}{|c|c|c|c|c|c|c|}
\hline Groups & Tests & $\begin{array}{l}\text { Mean } \\
\text { Arithmetic } \\
\text { Differences }\end{array}$ & $\begin{array}{l}\text { Deviation } \\
\text { Standard } \\
\text { Differences }\end{array}$ & $\begin{array}{l}\text { Value T } \\
\text { Calculated }\end{array}$ & $\begin{array}{l}\text { Level } \\
\text { Significanc }\end{array}$ & $\begin{array}{l}\text { Meaning } \\
\text { Significance }\end{array}$ \\
\hline \multirow{2}{*}{ Experimental } & Pretest & \multirow{2}{*}{4.150} & \multirow{2}{*}{1.226} & \multirow{2}{*}{15.140} & \multirow{2}{*}{0.00} & \multirow{2}{*}{ Moral } \\
\hline & Posttest & & & & & \\
\hline \multirow{2}{*}{ Regulation } & Pretest & \multirow{2}{*}{2.900} & \multirow{2}{*}{0.788} & \multirow{2}{*}{16.457} & \multirow{2}{*}{0.00} & \multirow{2}{*}{ Moral } \\
\hline & Posttest & & & & & \\
\hline
\end{tabular}

*Value $(\mathrm{T})$ cross tabulated when you 38 degree of freedom and the prospect of error $0.01=2.750$

Table (4). Shown variances a performance skills and the theoretical test experimental group and the control group in the tests are the tribal.

\begin{tabular}{|c|c|c|c|c|c|c|}
\hline Tests & Groups & $\begin{array}{l}\text { Mean } \\
\text { Arithmetic }\end{array}$ & $\begin{array}{l}\text { Deviation } \\
\text { Standard }\end{array}$ & $\begin{array}{l}\text { Value T. } \\
\text { Calculated }\end{array}$ & $\begin{array}{l}\text { Level } \\
\text { Signific } \\
\text { ance }\end{array}$ & $\begin{array}{l}\text { Meaning } \\
\text { Significance }\end{array}$ \\
\hline \multirow[b]{2}{*}{$\begin{array}{l}\text { Test } \\
\text { Skills }\end{array}$} & The experimental group & 3.350 & 0.988 & \multirow[b]{2}{*}{0.161} & \multirow[b]{2}{*}{0.873} & Moral not \\
\hline & The control group & 3.300 & 0.979 & & & \\
\hline \multirow{2}{*}{$\begin{array}{l}\text { Test } \\
\text { Theore } \\
\text { tical }\end{array}$} & The experimental group & 3.900 & 1.119 & \multirow[b]{2}{*}{0.941} & \multirow[b]{2}{*}{0.353} & Moral not \\
\hline & The control group & 3.600 & 0.883 & & & \\
\hline
\end{tabular}

Table (5). The values of $(v)$ of the tests and theoretical skills between the two groups for the posteriori measurements

\begin{tabular}{|c|c|c|c|c|c|c|}
\hline Tests & Groups & $\begin{array}{l}\text { Mean } \\
\text { Arithmetic }\end{array}$ & $\begin{array}{l}\text { Deviation } \\
\text { Standard }\end{array}$ & $\begin{array}{l}\text { Value T. } \\
\text { Calculated }\end{array}$ & $\begin{array}{l}\text { Level } \\
\text { Significance }\end{array}$ & $\begin{array}{l}\text { Meaning } \\
\text { Significance }\end{array}$ \\
\hline \multirow[b]{2}{*}{ skills Test } & $\begin{array}{l}\text { The experimental } \\
\text { group }\end{array}$ & 8.05 & 0.99 & \multirow[b]{2}{*}{7.84} & \multirow[b]{2}{*}{0.00} & Moral \\
\hline & The control group & 5.65 & 0.93 & & & \\
\hline \multirow[b]{2}{*}{$\begin{array}{l}\text { Theoretic } \\
\text { al Test }\end{array}$} & $\begin{array}{l}\text { The experimental } \\
\text { group }\end{array}$ & 8.05 & 0.99 & \multirow[b]{2}{*}{7.85} & \multirow[b]{2}{*}{0.00} & Moral \\
\hline & The control group & 5.75 & 0.85 & & & \\
\hline
\end{tabular}


Article theory was received by the respondents in the experimental effective access to private information about the performance of technical skill required to jump groundbreaking if it receives the sample corner importance occurring during the performance and the importance of exerting power in a short time And information on the path to the center of body during takeoff and touch the platform and the information associated with the second laws of Newton and the momentum who the students received during their studies theory.

As well as the to clarify the importance of take the appropriate angles in the joints of the body for the moment starting and Aviation to their importance in retaining an inertial required to continued state of body's the kinetic or a the fixed one of the scientific foundations associated with the process of learning and control equitably diagonals the body when application to the of performance this skill.

\section{THE CONCLUSIONS AND RECOMMENDATIONS:}

The conclusions:

That information the theoretical to Biomechanics obtained by the requesting studied the impact of AlBiomechanics had a positive effect on of performance for the skill jumping.

Raise the level of performance of female students for the skill jumping device opened a platform jumping.

The recommendations:

Necessity to focus on the foundations and the principles mechanical training on educational curricula according to the terms motor performance.

Emphasize the importance of the use of filming to see the errors occurring in the paths the kinetic performance of artistic for the sport of gymnastics.

The teaching staff input material linking artistic gymnastics and science Al-Biomechanics together in the field of teaching with correct the mechanical conditions accompanying the performance of artistic sport artistic gymnastics.

\section{REFERENCES}

1 Mandalawi, Q. et al. (1990). Tests and measurement in physical education: (Mosul Press, Higher Education)

2 Jabir, M., Ghaida, M.Y. (2004) Modified method to catch fingers tug in the sport of archery. Research published in the Faculty of Physical Education for Boys. (University of Alexandria) 